\title{
Kommentar zum Artikel „Die Lohngestaltung in der Tschechischen Republik“ von Zuzana Dvoráková
}

\author{
Ivan Nový*
}

Trotz der deutlichen positiven Verschiebung in der Wahrnehmung und in der praktischen Ausnutzung von psychologischen und sozial-psychologischen Erkenntnisse auf dem Gebiet der Stimulierung und Motivierung im Arbeitsprozeß bleibt die Frage des Gehalts auch weiterhin ein Schlüsselmoment der Personalleitung. Oft jedoch nicht nur das entscheidende, sondern auch das einzige Moment.

Die Problematik der Entlohnung hat eine neue Dimension bekommen und völlig ihre ursprüngliche Nivellierung und Disproportion zwischen der Entlohnung der physischen und geistigen Arbeit verloren (zu dem eindeutigen Ungunsten der geistigen Arbeit). Obwohl die Marktwirtschaft der Tschechischen Republik die Grundparameter der Marktwirtschaften von hochentwickelten Ländern verhältnismäßig schnell übernommen hat, ist weiterhin das gesamte Gebiet der Entlohnung als eines von vielen Problemen geblieben. Die innerbetrieblichen Lohnsysteme haben ihre innere Logik und sie könnten auch einen Stimulierungseffekt haben. Es sind jedoch sehr schnell neue, differenzierende Linien entstanden, bei denen Volumen und Arbeitsqualität praktisch keinen Zusammenhang mehr haben, und sie untergraben die Wirksamkeit der Lohnsysteme sehr.

Es handelt sich vor allem um eine ausgesprochene Disproportion zwischen den einzelnen Wirtschaftszweigen, zwischen dem privaten und staatlichen Sektor, den Regionen sowie der leitenden und ausführenden Arbeit. Der Unterschied bei den durchschnittlichen Gehältern differenziert zwischen den Zweigen so stark, daß es teilweise Unterschiede bis zu 100\% gibt, und zwar ohne Rücksicht auf die Qualifizierungsstruktur. So beträgt das Gehalt im Schulwesen gerade mal die Hälfte des Gehaltes im Finanzwesen. Ebenso bleibt der staatliche Sektor hinter dem privaten Sektor zurück, wenn auch Arbeitsposition und Qualifizierung vergleichbar sind. Der Unterschied zwischen den Regionen aus dem Gesichtspunkt der Gehälter ist ohne Zweifel in vielen Ländern Europas üblich, die Unterschiede erreichen in der Tschechischen Republik jedoch mehr als 50\%. Ebenso ist die Belohnung der leitenden und ausführenden Arbeit den tiefgreifenden Veränderungen gerecht geworden. Jedoch erreicht die Belohnung

\footnotetext{
* Wirtschaftsuniversität Prag
} 
der Topmanager der in Konkurs gehenden Unternehmen für einheimische Verhältnisse außerordentliche Summen, die, paradoxerweise, dem mehr als 50fachen des Durchschnittslohnes entsprechen. Gerade diese Gründe sind in der Regel die, welche demotivierend wirken.

Vereinfachend kann man feststellen, daß es wichtiger ist, wo sie arbeiten was sie arbeiten, also mit welcher Qualifizierung und in welcher Qualität ich als Mitarbeiter die Arbeit ausführe. Wenn wir darüber hinaus die Tatsache noch hinzurechnen, daß das Lebensminimum und der Minimallohn beinahe auf identischem Niveau sind, verliert der letzte Grund sich im Arbeitsprozeß unter den Bedingungen der schnell anwachsenden Arbeitslosigkeit zu engagieren seine Kraft, nämlich durch Arbeit Finanzeinkommen zu erreichen. 